\title{
Affective states in job characteristics theory ${ }^{\dagger}$
}

\author{
RICHARD SAAVEDRA ${ }^{1 *}$ AND SEOG K. KWUN ${ }^{2}$ \\ ${ }^{1}$ Department of Psychology, The University of Michigan, 525 East University Dr., Ann Arbor, \\ MI 48109-1109, U.S.A \\ ${ }^{2}$ Department of Business Administration, Hankuk University of Foreign Studies, Seoul, 130-791 Korea
}

Summary

\begin{abstract}
The potential consequences of affective experience at work prompt an examination of whether job characteristics are related to affect. Using two measurement models, we examined associations between perceptions of five job characteristics and self-reported mood. One model was based on traditional measures of 'positive' and 'negative' affect. The second model utilized a more differentiated measurement scheme consisting of four unipolar mood scores. Using both approaches achieves both broad and specific assessments of the links between affective states and job characteristics. Regression analyses of the survey data from 370 managers in 26 organizations indicated that job characteristics explained an average of 19 per cent of the variance in activated pleasant affect and an average of 11 per cent of the variance in activated unpleasant affect. Task significance and task autonomy were positively associated with activated pleasant affect. Skill variety was positively related, and task identity and task feedback were negatively correlated with activated unpleasant affect. Finally, Growth Need Strength (GNS) moderated the relation between the Motivating Potential Score (MPS) from the combined job characteristics and both activated pleasant and activated unpleasant affect. Using a four-factor model of affect (enthusiasm, fatigue, nervousness, and relaxation), we discuss preliminary implications for the design of work. Copyright (C) 2000 John Wiley \& Sons, Ltd.
\end{abstract}

\section{Introduction}

In the face of accumulating evidence on the consequences of affect, we know much less about the possible sources of affect, especially those factors relating to the organizational context. Typically, research relating to the consequences of affect has used small gifts, rewards, films, imagery, or audio stimuli to induce an affective state (Isen and Baron, 1991). The extent that this set of stimuli corresponds to the effects of organizational features has not been examined. Thus, the influence of the work context on affective experience remains largely unexplored (Burke et al., 1989; Burke and Pearlman, 1988). Moreover, the possibility of meaningfully distinct affective experiences at work has been generally ignored by researchers (Weiss and Cropanzano, 1996).

Weiss and Cropanzano (1996) have proposed a framework to explain the structure, causes, and consequences of affective experiences at work. They label their framework Affective Events

* Correspondence to: Richard Saavedra, Department of Psychology, The University of Michigan, 525 East University Dr., Ann Arbor, MI 48109-1109, U.S.A. E-mail: saavedra@umich.edu

$\dagger$ We appreciate the helpful comments of Lance Sandelands and Rick Price on an early version of this manuscript. The latest version of the paper includes the editorial and substantive contributions we received from Neal Ashkanasy and Cynthia Fisher as well as from two anonymous reviewers. 
Theory (AET), and they focus on workplace events as proximal causes of affective reactions. Weiss and Cropanzano propose that features of the work environment set up a structure in which certain affective events are more or less likely to take place. Affective experience in the workplace leads to consequences that are both attitudinal and behavioral (Weiss and Cropanzano, 1996). Work attitudes are influenced by affective experiences, which in turn influence cognitive judgment-driven behaviors. Affective experiences also result in affect-driven behaviors that follow directly from affective experiences.

Job characteristics are stable aspects of the work environment that could influence the affective experience of work. Cognitive appraisal theories suggest that an event is initially evaluated for relevance to personal well being (Frijda, 1986). In a work setting, such relevance may relate to whether job characteristics generate events that are congruent (beneficial) or incongruent (harmful) to the pursuit of personal goals (Weiss and Cropanzano, 1996). This initial appraisal also includes an evaluation of the importance or relevance of the event which, in turn, influences the intensity of the affective reaction. Appraisals of benefits (goal facilitation) lead to pleasant affective states; appraisals of impediments (goal obstruction) lead to unpleasant affective states (Weiss and Cropanzano, 1996). The intensity of the affective reaction is elevated for important events and flat for unimportant events.

To date, the job characteristics model (JCM) of Hackman and Oldham $(1975 ; 1976)$ has generated a great deal of research and debate relating to how perceptions of the task environment influence employee outcomes (Aldag et al., 1981; Gardner and Cummings, 1988; Roberts and Glick, 1981; Spector and Jex, 1991). According to Hackman and Oldham (1980, p. 60), if certain characteristics are present in a job, 'then jobholders will experience a positive, self-generated affective 'kick' when they perform well and this internal reinforcement serves as an incentive for continued good performance.' Although various outcomes have been examined in conjunction with job characteristics, including job satisfaction (Gerhart, 1987; Hackman and Oldham, 1980), psychological strain (Spector et al., 1988; Spector and Jex, 1991), and organizational commitment (Mathieu and Zajac, 1990), the current study explicitly links job characteristics to mood states as a way to gauge 'true' affective experiences (Weiss and Cropanzano, 1996).

Generally, individuals respond affectively to jobs based on their perceptions of job attributes (Brass, 1981; Hackman and Oldham, 1976; Oldham and Hackman, 1981; Rousseau, 1977, 1978a,b). Numerous studies suggest that perceptions of task characteristics function as antecedents of affective reactions (Champoux, 1991; Fried and Ferris, 1987; Gerhart, 1988; Hackman and Lawler, 1971; Hackman and Oldham, 1976; Locke, 1976; Loher et al., 1985). Whereas the relationship between affective reactions and perceived task characteristics may be reciprocal over time, the primary direction appears to be from perceived characteristics to affective reactions (James and Tetrick, 1986). Affect based on the job can, in turn, influence several well-studied outcomes such as commitment, job satisfaction, evaluative judgments, cooperation, extra-role behavior, conflict, information processing, and risky behavior (Isen and Baron, 1991; Weiss and Cropanzano, 1996). The potential consequences of affective experience urge an examination of whether job characteristics are related to affect at work.

In this research we assessed the association between perceptions of job characteristics and affective states. To measure affective states, we used the Job Affect Scale (JAS) developed by Brief et al. (1988). The JAS emphasizes differences in both valence and activation. Empirical work with the JAS suggests that affect is represented best as four factors (Burke et al., 1989; Brief et al., 1988). In the current study, we conduct our analyses using both the four-factor model and the traditional two-factor model of 'positive' and 'negative' affect. Using both measurement schemes, we are able to discern substantive differences in the two approaches to measuring mood at work. Finally, the job characteristics model examines individual responses as a function of the 
interaction of task perceptions and Growth Need Strength (GNS), an individual disposition. In the present study, we hypothesized that GNS would influence the relationship between the Motivating Potential Score (MPS) from the combined job characteristics and both activated pleasant and activated unpleasant affect.

\section{The measurement of affective states}

Moods are most frequently distinguished from emotions by three features: intensity, duration, and diffuseness (Frijda, 1993). In the current research, we focus on moods as mild, diffuse, and relatively enduring affective states (Isen and Baron, 1991; Forgas, 1992). We use the circumplex model of affect as an organizing framework (see Figure 1). The circumplex consists of mood categories that are symmetric, fully dimensional, and reflect the content of the mood states they represent. The dimensional structure of the circumplex has received strong empirical support (Larsen and Diener, 1992; Weiss and Cropanzano, 1996). The circumplex model accounts for the majority of the variance in mood measures used in research today and it labels mood states clearly and logically (Larsen, 1987; Larsen and Diener, 1992; Russell, 1989; Watson and Tellegen, 1985; Weiss and Cropanzano, 1996).

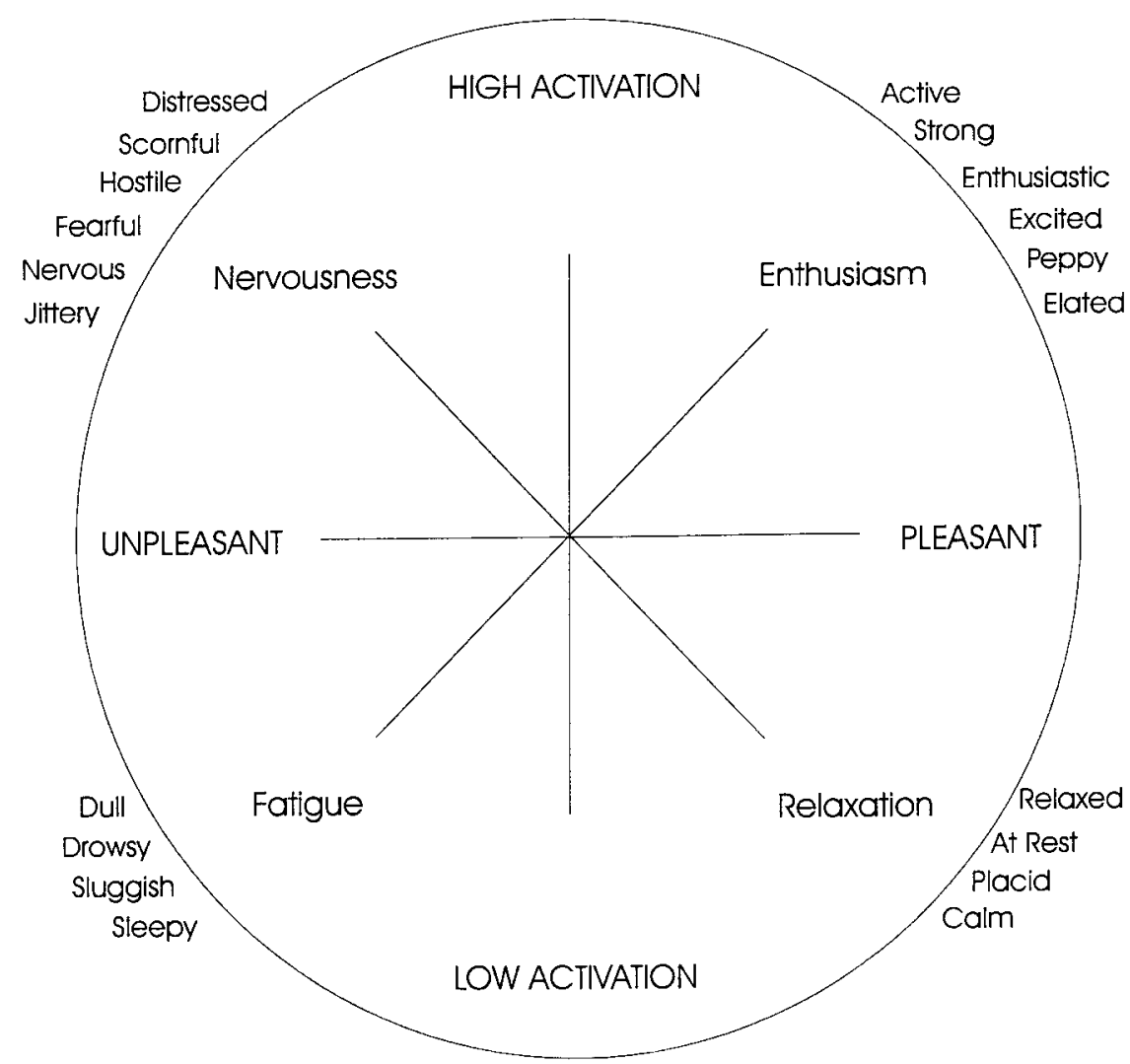

Figure 1. The location of the Job Affect Scale in the circumplex space defined by the self-report Affect Circumplex (adapted from Larsen and Diener, 1992) 
The circumplex model suggests that all moods share two basic, orthogonal dimensions (Larsen and Diener, 1992). One dimension reflects hedonic valence (pleasant-unpleasant/good-bad) and the second dimension includes behavioral readiness or arousal (high or low activation/important or unimportant). A plot of mood adjectives results in a circular structure relative to these two dimensions (Rusting and Larsen, 1995). At 45 degrees to the high-low activation and pleasantunpleasant dimensions, two additional dimensions further divide this circumplex structure. These two, bipolar orthogonal dimensions reflect a composite of hedonic valence and activation (activated-pleasant versus unactivated-unpleasant, and activated-unpleasant versus unactivatedpleasant). Typically, most mood research has utilized the familiar 'positive' and 'negative' affective dimensions. A review of previous measurement work indicates that, generally, 'positive affect' equates to activated pleasant affect while 'negative affect' equates to activated unpleasant affect (Larsen and Diener, 1992).

\section{The job characteristics model}

Job characteristics theory predicts attitudes and behavior based on the reactions of job incumbents to their tasks. The impact of a job on a person is moderated by a person's needs (Oldham, 1976; Oldham et al., 1976). According to Hackman and Oldham (1980), if certain characteristics are present in a job, jobholders will be internally motivated to perform well because certain needs will be met. This sequence is explicit in Hackman and Oldham's (1980) explanation of the 'motivating potential' of jobs. Increasing the motivating potential signifies the degree to which jobs are 'enriched' in that they provide for the fulfillment of growth needs (Gardner and Cummings, 1988). Growth needs, in turn, focus on the development of human potential and the desire for personal growth and increased competence (Alderfer, 1972).

Five core job characteristics define the motivating potential of a job: skill variety, task identity, task significance, task autonomy, and task feedback. Skill variety is the opportunity to use numerous and varied skills in one's personal repertoire to perform the work. Task identity is the degree to which the job requires the completion of a whole, recognizable piece of work. Task significance is the degree to which a job affects the lives of other people. Task autonomy is the extent to which the job provides individual discretion relating to the work process. Task feedback is the well-defined opportunity to know how effectively one is performing directly from the job itself. For the most part, confirmatory factor analyses have supported Hackman and Oldham's a priori structure for the five job characteristics (Champoux, 1991; Harvey et al., 1985). The aggregate effect of job characteristics on motivation is gauged with the MPS.

We hypothesized that all of the job characteristics - skill variety, task identity, task significance, task autonomy, and task feedback - would relate positively to activated pleasant affect. Moreover, Spector's work suggested that, with the exception of skill variety, all job characteristics correlate negatively and significantly with anxiety and frustration (Spector and Jex, 1991; Spector et al., 1988), implying that most job characteristics may also be significantly and negatively correlated with activated unpleasant affect. Skill variety requires a demonstration of an employee's personal skill and competency repertoire and is apt to promote some performance distress, especially for individuals with a low level of Growth Need Strength (GNS) (Hackman and Oldham, 1980) or perhaps another dispositional variable such as low self-efficacy. Thus, we expected that skill variety would be positively related while the other four characteristics would be negatively related to activated unpleasant affect. 


\section{Growth Need Strength}

GNS is the degree to which individuals have needs for accomplishment, for learning, and for personal development (Hackman and Oldham, 1980, p. 85). Hackman and Oldham (1980) argue that people with high GNS will experience enriched job characteristics more positively and will respond more positively in terms of internal work motivation and performance than low GNS counterparts. Support for the role of GNS in the job characteristics model is mixed, but generally the research suggests that GNS affects the magnitude but not the direction of the relations between job characteristics and affective outcomes (Aldag et al., 1981; Champoux, 1991, 1992; Spector, 1985).

Activated pleasant (positive) affect depends on need satisfaction, especially of higher order needs. If managers have their developmental needs met with enriched work, they should perceive job attributes as benefits and they should experience pleasant affect from their employment. In contrast, managers may experience unpleasant affect as a result of work designed to challenge and motivate which they may experience personally as a liability. Comparisons of high- versus low-GNS managers should indicate differences in the magnitude, but not the direction of the relation between job characteristics and affective experience. Both high- and low-GNS managers should generally perceive the managerial work situation as important and should, therefore, react with intensity to job characteristics. Thus, we expected GNS to moderate the relationship between the MPS from the combined job characteristics and both activated pleasant and activated unpleasant affect.

\section{Predictions}

We hypothesized that task identity, task significance, task autonomy, and task feedback would relate positively to activated pleasant affect and negatively to activated unpleasant affect. We predicted that skill variety would relate positively to both activated pleasant and activated unpleasant affect. We hypothesized that GNS would moderate relations between the MPS score from the combined job characteristics and both activated pleasant and activated unpleasant affect.

\section{Method}

\section{Sample}

We used a survey to collect perceptions of job characteristics and of affect. We were concerned with two sampling issues related to survey research using the JDS. First, Brief and Aldag (1978) reported that the psychometric integrity of the JDS was not preserved with homogeneous samples. Second, the JDS is designed to assess variation across jobs, not across individuals within the same job categories (Roberts and Glick, 1981). Hence, we restricted our sample to those individuals engaged in managerial work broadly defined to collect a representative sample, but we sampled across a broad number of functional specialties as well as industries to survey heterogeneous jobs. Hence, this study dealt with naturally occurring task differences that are a function of the distinct jobs of different individuals.

Participants were 370 managers from 26 organizations engaged in service $(n=15)$, sales $(n=6)$, or manufacturing $(n=5)$ work in a major Midwestern city in the U.S., and 76 per cent of those asked responded to the survey. The 26 organizations represented a convenience sample 
selected on the basis of contacts with managers enroled in an evening MBA program. To minimize organizational effects, we restricted the number of respondents from each organization to approximately 15 individuals. Of the 370 respondents who fully participated, 57.1 per cent were female. We used categories to gather age information and most of the respondents ( 78.9 per cent) reported they were between 20 and 39 years of age.

We compared the means and variance of the five job characteristics, GNS, and MPS of our sample against published norms for the Job Diagnostic Survey (Hackman and Oldham, 1980). A comparison of sample means for the Managerial Job Family of the JDS revealed systematic patterns. First, our sample indicated lower means on all job characteristics with the exception of task identity and it also demonstrated a relatively lower MPS. Second, our sample evidenced moderately greater standard deviations than the normative sample. However, the mean GNS for our sample was exactly the same as published norms for this job family. Overall, we suspect that the variance in our sample derived from the fact that although we surveyed managers, the work itself varied by the nature of the employing organization's core business-sales, service, or manufacturing.

\section{Independent measures}

Task dimensions. Standard measures for the five core job dimensions were obtained from Hackman and Oldham (1980) based on the Job Diagnostic Survey (JDS) (Hackman and Oldham, 1975, 1976). The JDS measures the amounts of task identity, variety, significance, autonomy, and feedback from the job. Three items on the questionnaire tap each characteristic. Items were averaged to obtain the score for each characteristic. Overall, intercorrelations among JDS variables ranged from -0.02 to 0.50 with a mean of 0.23 . The reliabilities ranged from 0.64 to 0.79 with a median of 0.70 . These reliabilities are almost identical to those reported by Champoux (1992) and compare favorably with the published reliabilities of JDS norms (Oldham et al., 1979).

Growth Need Strength. We used the JDS job choice measure of GNS following research suggesting that it provides a sounder and more relevant measure of growth needs (Aldag and Brief, 1979). The 12 separate items were averaged to form a summary score. Coefficient alpha for this measure was 0.90 .

\section{Dependent measures}

Affective states were measured using the Job Affect Scale developed by Brief et al. (1988). The JAS is a 20-item self-report instrument that measures two orthogonal, bipolar mood dimensions. The JAS dimensions reflect both hedonic valence and activation. The four 'poles' of the two JAS dimensions are Enthusiasm and Fatigue, and Nervousness and Relaxation, respectively.

The adjectives for each of the four poles follow: Enthusiasm - active, strong, excited, enthusiastic, peppy, elated (Cronbach's alpha $=0.83$ ). Relaxation - calm, relaxed, at rest, placid $($ Cronbach's alpha $=0.85)$. Nervousness-distressed, scornful, hostile, fearful, nervous, jittery $($ Cronbach's alpha $=0.83)$. Fatigue - sleepy, dull, drowsy, sluggish (Cronbach's alpha $=0.88)$.

To calculate bipolar dimensions, we subtracted the two opposing poles of a dimension and named the vector in the direction of the first vector in the equation: activated pleasant affect $=$ enthusiasm - fatigue; activated unpleasant affect $=$ nervousness - relaxation. These 
two general composites reflect the two-factor solution described in Burke et al. (1989, p. 1096). The two-factor approach has also been used successfully in other research (Saavedra and Earley, 1991) and is both theoretically and empirically supported (Larsen and Diener, 1992).

We compared the two- and four-factor models of the JAS to see if a four-vector solution would further illuminate the relationships between job characteristics and affect. The circumplex model of affect suggests that either of the two solutions would be theoretically appropriate. Four-factor solutions of the JAS have been confirmed elsewhere (Burke et al., 1989; Saavedra and Earley, 1991).

Based on Brief et al. (1989), respondents in our study received the following instructions. 'For each of the following items, indicate the extent to which it characterizes how you felt at work during the past week using the following scale.' The 6-point scale ranged from 'Disagree Strongly' (1) to 'Agree Strongly' (6).

\section{Results}

Before beginning our analyses, we examined the data for non-linear effects by using squared regression coefficients as well as by inspecting variable plots for evidence of non-linear relationships. We found no evidence for non-linearity in this data set.

\section{Correlational analyses}

Table 1 displays descriptive statistics and intercorrelations among the study variables. Coefficient alpha reliability estimates for these measures are displayed in parentheses along the diagonal of the correlation matrix.

GNS was not significantly correlated with either activated pleasant or activated unpleasant affect. Job characteristics exhibited distinct patterns with affective dimensions in Table 1. Skill variety, task significance, and task feedback were significantly and positively related to activated pleasant affect. Task identity was significantly and negatively related to activated unpleasant affect. Skill variety was significantly and positively related to both activated pleasant affect and activated unpleasant affect. Taken collectively, these relationships suggest that job characteristics were associated with both activated pleasant affect and activated unpleasant affect.

In terms of demographic differences, our correlational analyses did not indicate significant sex differences. However, relatively older individuals were more likely to report activated pleasant affect. These managers also responded to the JDS questions in a way that suggested that, in contrast to younger managers, they experienced their jobs as more motivating. Individuals that held longer tenure in their organizations also reported greater activated pleasant affect and indicated by their pattern of responses to job characteristics that they experienced their jobs as more motivating than did managers with less tenure. We examined the confounding effects of age and tenure in subsequent regression analyses. For activated pleasant affect, age and tenure jointly accounted for 1 per cent of the variance. For activated unpleasant affect, these two variables did not account for significant variation. Given that they only accounted for a slight fraction of the variance, we decided not to include demographic control variables in our analyses. 
Table 1. Descriptive statistics and intercorrelations among study variables

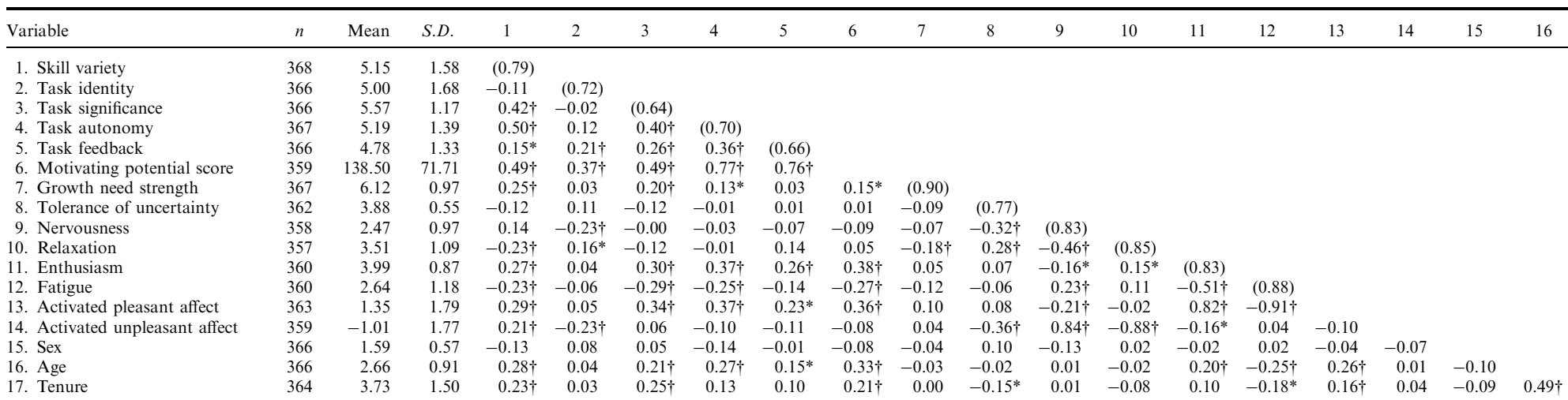

Note: Tests of significance are two-tailed.

$n=370 ;{ }^{*} p<0.01 ; \dagger p<0.001$.

Bipolar dimension calculations:

$[$ Activated Pleasant $]=[$ Enthusiasm $]-[$ Fatigue $]$

[Activated Unpleasant $]=[$ Nervousness $]-[$ Relaxation $]$. 
Table 2. Regression analyses of affective dimensions on job characteristics

\begin{tabular}{lccccc}
\hline Independent variables & \multicolumn{2}{c}{ Activated pleasant } & & \multicolumn{2}{c}{ Activated unpleasant } \\
\cline { 2 - 3 } \cline { 5 - 6 } & Beta & $t$-value & & Beta & $t$-value \\
\hline Skill variety & 0.099 & 1.682 & & 0.235 & $3.837 \dagger$ \\
Task identity & 0.024 & 0.480 & & -0.175 & $-3.362 \ddagger$ \\
Task significance & 0.204 & $3.672 \ddagger$ & & 0.056 & 0.963 \\
Task autonomy & 0.197 & $3.226 \dagger$ & & -0.086 & -1.345 \\
Task feedback & 0.067 & 1.284 & & -0.119 & $-2.172^{*}$ \\
$R^{2}$ & 0.188 & & & 0.114 & \\
$F$ & $16.65 \ddagger$ & & & $9.31 \ddagger$ & \\
\hline
\end{tabular}

Note: $n=365$.

${ }^{*} p<0.05 ; \dagger p<0.01 ; \ddagger p<0.001$.

\section{Job characteristics as predictors of affect}

We predicted that four of the five job characteristics, because they are presumed to prompt enthusiastic reactions to work, would be positively and significantly associated with activated pleasant affect and significantly and negatively related to activated unpleasant affect. Skill variety, because it can induce nervousness, should be significantly and positively related to activated unpleasant affect. To test these propositions, we regressed the two affective dimensions on the five job characteristics. Table 2 presents these results and we describe the highlights below.

Overall, job dimensions explained an average of 19 per cent of the variance in activated pleasant affect and an average of 11 per cent of the variance in activated unpleasant affect. Task significance and task autonomy were positively and significantly related to activated pleasant affect, partially supporting our original predictions. As expected, task identity and task feedback were negatively and significantly related to activated unpleasant affect. Finally, as hypothesized, skill variety was positively and significantly related to activated unpleasant affect, but it was not significantly related to activated pleasant affect in conjunction with other job characteristics.

\section{A four-vector model of affect}

The four vectors in the JAS correspond to the two poles each of the activated pleasant/ unactivated unpleasant dimension and the activated unpleasant/unactivated pleasant dimensions in Figure 1. In essence, we decomposed the two bipolar dimensional vectors into four unipolar vectors, namely, enthusiasm, fatigue, nervousness, and relaxation.

We began by examining the pattern of correlations for the four factors of the JAS in Table 1. Generally, job characteristics serve to activate behavior in a pleasantly arousing manner. Neither nervousness nor relaxation were significantly related to MPS. In turn, MPS was significantly related to activated pleasant affect $(r=0.36, p<0.001)$, but not to activated unpleasant affect. An inspection of Table 1 shows that enthusiasm was most highly correlated with MPS $(r=0.38$, $p<0.001$ ), suggesting that enthusiasm is the affective state with the closest link to the type of job motivation that is the focus of job characteristics theory. Moreover, the opposite 'pole' of enthusiasm is fatigue, which was also significantly, but negatively, correlated with MPS $(r=-0.27, p<0.001)$. It may follow that, at its core, job redesign efforts may seek affectively to promote enthusiasm and relieve fatigue. 
Table 3. Regression analyses of the Job Affect Scale four-factor moods on job characteristics

\begin{tabular}{|c|c|c|c|c|c|c|c|c|}
\hline \multirow{2}{*}{$\begin{array}{l}\text { Independent } \\
\text { variables }\end{array}$} & \multicolumn{2}{|c|}{ Enthusiasm } & \multicolumn{2}{|c|}{ Fatigue } & \multicolumn{2}{|c|}{ Nervousness } & \multicolumn{2}{|c|}{ Relaxation } \\
\hline & Beta & $t$-value & Beta & $t$-value & Beta & $t$-value & Beta & $t$-value \\
\hline Skill variety & 0.095 & 1.616 & -0.079 & -1.304 & 0.175 & $2.796 \dagger$ & -0.226 & -3.669 \\
\hline Task identity & -0.010 & -0.194 & -0.043 & -0.840 & -0.211 & $-3.979 t$ & 0.097 & $1.846^{\circ}$ \\
\hline Task significance & 0.138 & $2.462 *$ & -0.208 & $-3.609 \%$ & -0.026 & -0.446 & -0.114 & -1.949 \\
\hline Task autonomy & 0.220 & $3.583 t$ & -0.137 & $-2.158 *$ & -0.066 & -1.018 & 0.080 & 1.252 \\
\hline Task feedback & 0.114 & $2.166^{*}$ & -0.018 & -0.330 & -0.040 & -0.713 & 0.157 & $2.856 \dagger$ \\
\hline$R^{2}$ & 0.177 & & 0.126 & & 0.082 & & 0.104 & \\
\hline$F$ & $15.491 \%$ & & $10.425 \%$ & & $6.407 \%$ & & $8.356 \%$ & \\
\hline
\end{tabular}

Note: $n=365$.

$* p<0.05 ; \dagger p<0.01 ; \ddagger p<0.001$.

Table 4. The main and moderating effects of Growth Need Strength (GNS) on the relationship between affective states and the Motivating Potential Score (MPS) for the combined job characteristics

\begin{tabular}{|c|c|c|c|c|c|}
\hline \multirow[t]{2}{*}{ Affective dimensions } & \multirow{2}{*}{$\begin{array}{l}\text { Independent } \\
\text { variables }\end{array}$} & \multicolumn{2}{|c|}{ Multiple regression model } & \multicolumn{2}{|c|}{ Hierarchical analysis } \\
\hline & & Beta & $t$-value & $R^{2}$ & $F$ \\
\hline \multicolumn{6}{|l|}{ Activated pleasant } \\
\hline Model 1 & MPS & 0.374 & $7.689 \$$ & 0.140 & $59.12 \ddagger$ \\
\hline \multirow{3}{*}{ Model 2} & MPS & -0.209 & -0.732 & & \\
\hline & GNS & -0.115 & -1.201 & & \\
\hline & MPS $\times$ GNS & 0.633 & $2.044^{*}$ & 0.153 & $21.66 \%$ \\
\hline \multicolumn{6}{|l|}{ Activated unpleasant } \\
\hline Model 1 & MPS & -0.089 & -1.703 & 0.008 & 2.99 \\
\hline \multirow[t]{3}{*}{ Model 2} & MPS & 0.462 & 1.510 & & \\
\hline & GNS & 0.244 & $2.375^{*}$ & & \\
\hline & MPS $\times$ GNS & -0.624 & -1.875 & 0.023 & $2.89 *$ \\
\hline
\end{tabular}

Note: $n=364$

$* p<0.05 ; \dagger p<0.01 ; \ddagger p<0.001$.

The four mood poles of the JAS were each regressed on the five job characteristics. Table 3 presents these results and we describe the highlights below. As a set, job characteristics contributed 18 per cent of the variance in enthusiasm and 12 per cent of the variance in fatigue. As a set, they contributed 8 per cent and 10 per cent to nervousness and relaxation, respectively.

Viewed through a four-factor measurement scheme, each job characteristic exerted fairly unique effects. Task significance, task autonomy, and task feedback were positively and significantly related to enthusiasm. Task significance was also negatively and significantly related to fatigue. Skill variety was positively and significantly related to nervousness, and negatively and significantly related to relaxation. Task identity was negatively and significantly related to nervousness. Finally, task feedback was also positively and significantly associated with relaxation.

\section{GNS as moderator}

We used moderated regression analyses to test whether GNS moderated the relationship between the MPS and both activated pleasant and activated unpleasant affect. Table 4 presents the results 

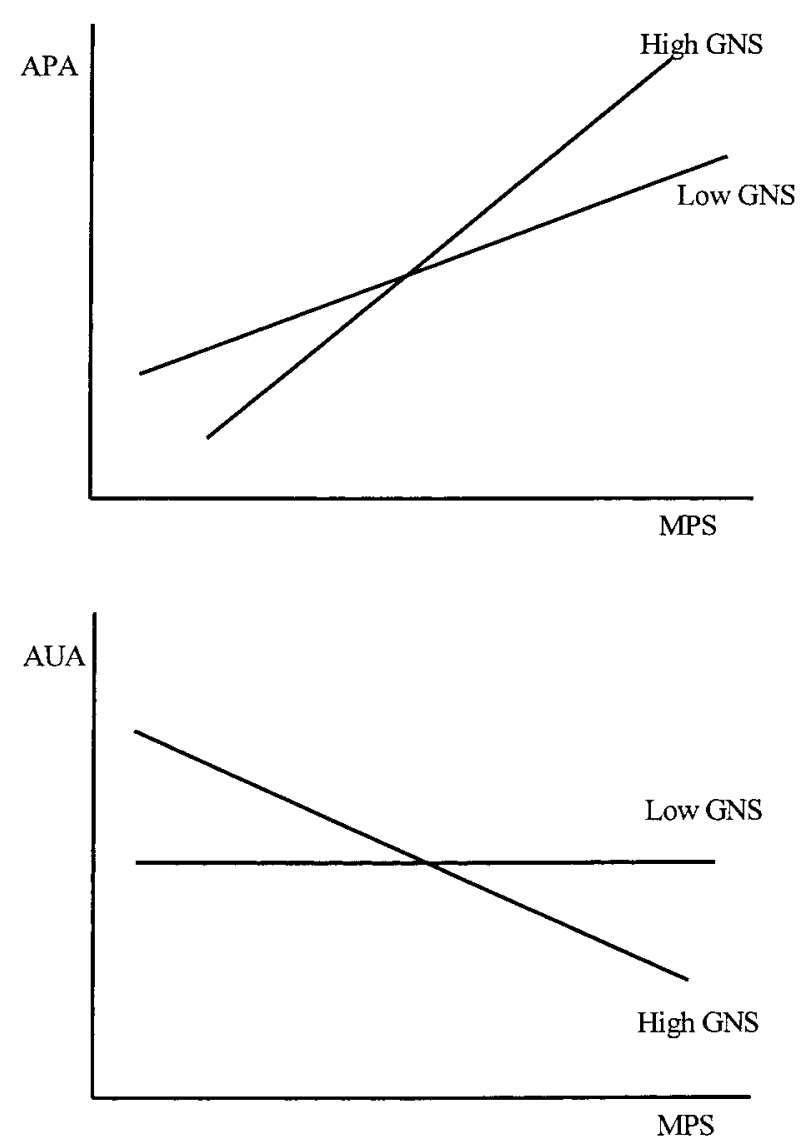

Figure 2. The interactive effects of Growth Need Strength (GNS) on the relationship between activated pleasant (APA) or activated unpleasant (AUA) affect and the Motivating Potential Score (MPS) from the Job Characteristics Model

of two hierarchical regression models for both activated pleasant affect and activated unpleasant affect.

The hierarchical analysis revealed that GNS moderated the relationship between job characteristics and both activated pleasant affect and activated unpleasant affect, thus supporting its hypothesized moderating roles. In Figure 2 we see that high-GNS managers demonstrate a stronger positive relation between activated pleasant affect and MPS than low-GNS managers. We also see that high-GNS managers indicate a strong and negative relation between activated unpleasant affect and MPS. In contrast, low-GNS managers indicate an insignificant relationship between activated unpleasant affect and MPS.

\section{Discussion}

We examined whether perceptions of job characteristics related to activated pleasant affect and activated unpleasant affect. The findings suggest that those characteristics that relate to the 
motivating potential of a job also relate to affective experience at work. Task identity and task feedback were negatively related to activated unpleasant affect. Skill variety was positively associated with activated unpleasant affect. Task significance and task autonomy were positively related to activated pleasant affect and are probably the characteristics most directly related to the 'affective kick' described by Hackman and Oldham (1980).

GNS moderated associations between MPS and both activated pleasant affect and activated unpleasant affect. GNS moderation is such that high-GNS managers should report more activated pleasant affect as well as less activated unpleasant affect in conjunction with enriched work. These results are compatible with research indicating that GNS usually changes the magnitude but not the direction of job characteristics - outcome relationships. Consistent with job characteristics theory, managerial work with a high motivating potential is better suited to high-GNS individuals. We suggest that a high level of GNS may be particularly important for managerial work requiring skill variety given that this job characteristic is positively associated with nervousness and negatively associated with relaxation.

We utilized two measurement models in our research. One model was based on traditional measures of 'positive' and 'negative' affect that reflect two bipolar scores, corresponding to a dimensional analysis in the mood circumplex. The second model utilized a more differentiated measurement scheme consisting of four unipolar mood scores. By using a two-factor model of affect we improved coherence and analysis logic, but we truncated the range of mood experience. The four-factor model represents a more fully differentiated affective experience that also more precisely illustrates relations between job characteristics and mood. Using four affective measures demonstrates that each job characteristic exerts distinctive effects. For example, using the fourfactor model we find that skill variety is not only positively related to nervousness, but that it also negatively associated with relaxation. Predictions using the traditional model of activated pleasant and activated unpleasant affect would hold only that skill variety is related to activated unpleasant affect. On balance, using both approaches achieves both broad and detailed assessments of the links between affective states and job characteristics.

\section{Implications for behavior}

Research has shown that mood states impact task motivation, information processing, and social behavior, producing varied effects on analytical reasoning, problem solving, decision-making, and creativity (Isen and Baron, 1991; Forgas, 1992; George and Brief, 1992; Staw and Barsade, 1993; Staw et al., 1994). We share the perspective that mood may be a major influence on social cognition (Hinsz et al., 1997). That is, moods that have a direct informational role on inferences (Clore and Parrott, 1991; Schwarz and Clore, 1988) and they inform us about states of the world that either do or do not require careful monitoring or processing (Frijda, 1986; Schwarz, 1990).

Positive affective states (activated pleasant mood) signal a benign and unproblematic situation while negative affective states indicate that a situation is troublesome, characterized by disappointment or threat (Bless et al., 1996). Individuals in negative affective states (activated unpleasant mood) focus on the specifics of the situation, reflecting that their mood signals a problematic situation that renders it risky to rely on one's default routines. Individuals in positive affective states perceive the situation as uncomplicated, suggesting that general habits would serve them reliably (Bless et al., 1996). Nevertheless, whereas mood has well documented effects on memory, judgment, and social behaviors, the performance implications of these effects depend upon the demands of the task (Weiss and Cropanzano, 1996). 
Task identity may prevent nervousness in managerial work perhaps because it circumscribes the domain of responsibility for managers. Task significance may prevent fatigue although the literature on burnout in social service workers would stand in direct contradiction. It would be interesting to examine the association between the degree to which an employee's work significantly affects the lives of others and affective states. In taking stock of their relative standing in an organization, managers may see task significance as a gateway to power in a way suggesting more is better for enthusiasm. For social service providers, task significance may signal role overload, strain, and a sense of hopelessness. Under such conditions, high levels of task significance could promote nervousness and fatigue. Accordingly, systematic subsample comparisons would enable researchers to compare the form of association between job characteristics and affective states (e.g., linear versus curvilinear).

Skill variety related positively to nervousness and negatively to relaxation. Managers that are nervous and aroused may find that they are more vigilant and that they perceive greater threat in their task environment. Managers in an activated unpleasant mood state are also more likely to engage in systematic information processing as a distraction to eliminate unpleasant mood (Sinclair and Mark, 1992). As a result, managers are likely to focus more analytically on the situation at hand, a clearly adaptive posture in uncertain environments. On this note, the informational role of negative affective states, especially as a stimulant to problem solving, has not been investigated systematically and would appear to be fertile ground for future study.

The current research on affect suggests paradoxical effects for managerial work in an activated pleasant mood state. Task autonomy and task significance were related to activated pleasant mood. These two job characteristics, in conjunction with task feedback, accounted for 18 per cent of the variance in enthusiasm. As mentioned previously, job redesign efforts may generally operate to increase enthusiasm and relieve fatigue. Task autonomy, task significance, and task feedback may serve to energize, reinforce and maintain work behavior. If we consider cognitive tasks to be fundamental managerial duties, managers may follow a hedonic contingency approach (Petty and Wegener, 1999) in responding to judgment and decision making taks. Managers in an activated pleasant mood are likely to engage in effortful processing for situations that are generally favorable and problem-free. However, they may engage in simplified, heuristic processing strategies during cognitive tasks under situations which may threaten their activated pleasant mood state. Task feedback may promote relaxation, most likely in situations where reliable routines service performance objectives (avoiding cognitive effort). On balance, a blend of affective experience, some pleasant, some not, may be of particular value for managers. Here again, we see that a more differentiated measurement scheme utilizing multiple mood states would serve job designers most effectively.

The foregoing analysis takes the tact that job characteristics exert their effects on behavior through their affective influence on cognition and motivation. An alternative point-of-view is that job holders experience the performance of a task that fosters experienced meaningfulness, experienced responsibility, and that allows knowledge of results, precisely the types of affective events Weiss and Cropanzano (1996) suggest should occur more often in enriched jobs. Such events should be the most immediate antecedents of activated pleasant and unpleasant mood while on the job. Hackman and Oldham (1980) would suggest it is this multifaceted job performance experience that provides the 'affective kick.' Future studies should assess job characteristics, affective events, and mood on multiple occasions to test these propositions.

In our study, we attempted to predict stable affect from stable job characteristics. Our results should be interpreted as associations between self-reports of cognition and affect that do not address the issue of causality. Second, as a cross-sectional study it was vulnerable to influences from organizational and personal sources. Nonetheless, we did not find any substantial 
confounding effects due to demographic variables - sex, age, or tenure. Third, both perceptions of job characteristics and affect were collected at the same time, increasing the risk of correlated measurement error. However, we asked respondents to gauge their moods over the course of the past week to increase the stability of the JAS reports.

\section{Design of managerial work}

Although the work presented here is preliminary, we can begin to formulate initial implications for the design of managerial work. Generally, job incumbents should be more enthusiastic when their job affects the lives of others, when they have the opportunity to make work-related decisions, and when they receive feedback from the task they are performing. Job holders should also feel less fatigued when their job affects others. They should feel less nervous if their job involves the completion of a whole, identifiable piece of work and they should be more relaxed when they receive task feedback. Finally, job holders should be more nervous and aroused when their jobs require many and varied skills. Taken to an extreme, a job with extensive demands for skill variety may be distressing.

Overall, we believe that the results of this research are generalizable to managerial work in other contexts and are useful as a preliminary study of perceptions and affect using the job characteristics model. The reliable psychometric properties of the constructs give further support to generalizability. Future work on affective states needs to address the links between affect and behavior both with managers and with a variety of populations such as personnel involved with sales, clerical work, technical or professional work, and machine trades. However, for prospective research on affect to be useful to job designers, job outcomes needs to be described in terms of requirements for information processing, for active problem solving, for behavior, and for performance. Accordingly, we can determine how affective states influence work strategies and we can configure a work system to enhance (or mitigate) targeted affective states to improve performance and the experience of work.

\section{References}

Aldag RJ, Barr SH, Brief AP. 1981. Measurement of perceived task characteristics. Psychological Bulletin 90: $415-431$.

Aldag RJ, Brief AP. 1979. Examination of a measure of higher order need strength. Human Relations 32: $705-718$.

Alderfer C. 1972. Existence, Relatedness, and Growth. Free Press: New York.

Bless H, Clore GL, Schwarz N, Golisano V, Rabe C, Wolk M. 1996. Mood and the sue of scripts: does a happy mood really lead to mindlessness? Journal of Personality and Social Psychology 71: 665-679.

Brass DJ. 1981. Structural relationships, job characteristics, and worker satisfaction and performance. Administrative Science Quarterly 26: 331-348.

Brief AP, Aldag RJ. 1978. The Job Characteristics Inventory: an examination. Academy of Management Journal 21: 659-671.

Brief AP, Burke MJ, George JM, Robinson BS, Webster J. 1988. Should negative affectivity remain an unmeasured variable in the study of job stress? Journal of Applied Psychology 73: 193-198.

Burke MJ, Pearlman K. 1988. Recruitment, selection, and matching people to jobs. In Productivity in Organizations, Campbell JP, Campbell RJ (eds); Jossey-Bass: San Francisco; 97-142. 
Burke MJ, Brief AP, George JM, Roberson L, Webster J. 1989. Measuring affect at work: confirmatory analyses of competing mood structures with conceptual linkage to cortical regulatory systems. Journal of Personality and Social Psychology 57: 1091-1102.

Champoux JE. 1991. A multivariate analysis of curvilinear relationships among job scope, work context satisfactions, and affective outcomes. Human Relations 45: 87-111.

Champoux JE. 1992. A multivariate test of the job characteristics theory of work motivation. Journal of Organizational Behavior 12: 431-446.

Clore GL, Parrott G. 1991. Moods and their vicissitudes: thoughts and feelings as information. In Emotion and Social Judgments, Forgas JP (ed.); Pergamon: Oxford; 107-123.

Forgas JP. 1992. Affect in social judgments and decisions: a multiprocess model. Advances in Experimental Social Psychology 25: 227-275.

Fried Y, Ferris GR. 1987. The validity of the job characteristics model: a review and meta-analysis. Personnel Psychology 40: 287-322.

Frijda NH. 1986. The Emotions. Cambridge University Press: Cambridge.

Frijda NH. 1993. Moods emotion episodes, and emotions. In Handbook of Emotions, Lewis M, Haviland JM (eds); Guildford Press: New York; 381-403.

Gardner DG, Cummings LL. 1988. Activation theory and job design: review and reconceptualization. Research in Organizational Behavior 10: 81-122.

George JM, Brief AP. 1992. Feeling good-doing good: a conceptual analysis of the mood at workorganizational spontaneity relationship. Psychological Bulletin 112: 310-329.

Gerhart B. 1987. How important are dispositional factors as determinants of job satisfaction? Implications for job design and other personnel programs. Journal of Applied Psychology 72: 366-373.

Gerhart B. 1988. Sources of variance in incumbent perceptions of job complexity. Journal of Applied Psychology 73: 154-162.

Hackman JR, Lawler EE III. 1971. Employee reactions to job characteristics. Journal of Applied Psychology Monograph 55: 259-286.

Hackman JR, Oldham GR. 1975. Development of the Job Diagnostic Survey. Journal of Applied Psychology 60: 159-170.

Hackman JR, Oldham GR. 1976. Motivation through the design of work: test of a theory. Organizational Behavior and Human Performance 16: 250-279.

Hackman JR, Oldham GR. 1980. Work Redesign. Addison-Wesley: Reading, MA.

Harvey RJ, Billings RS, Nilan KJ. 1985. Confirmatory factor anlaysis of the Job Diagnostic Survey: good news and bad news. Journal of Applied Psychology 70: 461-468.

Hinsz VB, Tindale RS, Volrath DA. 1997. The emerging conceptualizations of groups as information processors. Psychological Bulletin 121: 43-64.

Isen AM, Baron RA. 1991. Positive affect as a factor in organizational behavior. Research in Organizational Behavior 13: 1-53.

James LA, Tetrick LE. 1986. Confirmatory analytic tests of three causal models relating job perceptions to job satisfaction. Journal of Applied Psychology 71: 77-82.

Larsen RL. 1987. The stability of mood variability: a special analytic approach to daily mood assessments. Journal of Personality and Social Psychology 52: 1195-1204.

Larsen RL, Diener E. 1992. Promises and problems with the circumplex model of emotion. In Review of Personality and Social Psychology: Emotion and Social Behavior, Vol. 114, Clark MS (ed.); Sage: Newbury Park, CA; 25-59.

Locke EA. 1976. The nature and causes of job satisfaction. Handbook of Industrial and Organizational Psychology, Dunnette MD (ed.); Rand McNally: Chicago; 1297-1349.

Loher BT, Noe RA, Moeller NL, Fitzgerald MP. 1985. A meta-analysis of the relation of job characteristics to job satisfaction. Journal of Applied Psychology 70: 280-289.

Mathieu JE, Zajac D. 1990. A review and meta-analysis of the antecedents, correlates, and consequences of organizational commitment. Psychological Bulletin 108: 171-194.

Oldham GR. 1976. Job characteristics and internal motivation: the moderating effect of interpersonal and individual variables. Human Relations 29: 559-569.

Oldham GR, Hackman JR. 1981. Relationships between organizational structure and employee reactions: comparing alternative frameworks. Administrative Science Quarterly 26: 66-83.

Oldham GR, Hackman JR, Pearce JL. 1976. Conditions under which employees respond positively to enriched work. Journal of Applied Psychology 61: 395-403. 
Oldham GR, Hackman JR, Stephina LP. 1979. Norms for the job diagnostic survey. JSAS Catalog of Selected Documents in Psychology 9: , ms. no. 1819.

Petty RE, Wegener DT. 1999. Attitude change: multiple roles for persuasion variables. In The Handbook of Social Psychology, Vol. 1, Chpt. 8, Gilbert DT, Fiske ST, Lindzey G (eds); Oxford University Press: New York; 323-390.

Roberts KH, Glick W. 1981. The job characteristics approach to job design: a critical review. Journal of Applied Psychology 66: 193-217.

Rousseau DM. 1977. Technological differences in job characteristics, employee satisfaction, and motivation: a synthesis of job design research and sociotechnical systems theory. Organizational Behavior and Human Performance 19: 18-42.

Rousseau DM. 1978a. Measures of technology as predictors of employee attitudes. Journal of Applied Psychology 63: 213-218.

Rousseau DM. 1978b. Characteristics of departments, positions, and individuals: context for attitudes and behavior. Administrative Science Quarterly 23: 521-540.

Russell JA. 1989. Measures of emotion. In Emotion: Theory, Research, and Experience, Vol. 4, Plutchik R, Kellerman H (eds); Academic Press: New York; 83-111.

Rusting CL, Larsen RJ. 1995. Moods as sources of stimulation: relationships between personality and desired mood states. Personality and Individual Differences 18: 321-329.

Saavedra R, Earley PC. 1991. Choice of task and goal under conditions of general and specific affective inducement. Motivation and Emotion 15: 45-65.

Schwarz N. 1990. Feelings as information: informational and motivational functions of affective states. In Handbook of Motivation and Cognition: Foundations for Social Behavior, Vol. 2, Higgins ET, Sorrentino R (eds); Guilford: New York.

Schwarz N, Clore GL. 1988. How do I feel about it? The informative function of affective states. In Affect, Cognition, and Social Behavior, Fiedler K, Forgas JP (eds); Hogrefe International: Toronto.

Sinclair RC, Mark MM. 1992. The influence of mood state on judgment and actions: effects on persuasion, categorization, social justice, person perception and judgmental accuracy. In The Construction of Social Judgments, Martin LL, Tesser A (eds); Lawrence Erlbaum: Hillsdale, NJ; 165-193.

Spector PE. 1985. Higher-order need strength as a moderator of the job scope-employee outcome relationship: a meta analysis. Journal of Occupational Psychology 58: 119-127.

Spector PE, Jex SM. 1991. Relations of job characteristics from multiple data sources with employee affect, absence, turnover intentions, and health. Journal of Applied Psychology 76: 46-53.

Spector PE, Dwyer DJ, Jex SM. 1988. Relation of job stressors to affective, health, and performance outcomes: a comparison of multiple data sources. Journal of Applied Psychology 73: 11-19.

Staw BM, Barsade SG. 1993. Affect and managerial performance: a test of the sadder-but-wiser vs. happier-and-sadder hypothesis. Administrative Science Quarterly 38: 304-331.

Staw BM, Sutton RI, Pelled LH. 1994. Employee positive emotion and favorable outcomes at the workplace. Organization Science 5: 51-71.

Watson D, Tellegen A. 1985. Toward a consensual structure of mood. Psychological Bulletin 98: 219-235.

Weiss HM, Cropanzano R. 1996. Affective events theory: a theoretical discussion of the structure, causes, and consequences of affective experiences at work. Research in Organizational Behavior 18: 1-74. 